\title{
Empirical Analysis of Commercial Financing' Impact on Social Donations to Private Foundations
}

\author{
Li-Xin DAI ${ }^{1, a}$, Li-Ya JIANG ${ }^{2, b}$ \\ ${ }^{1,2}$ Department of Economics and Management, North China Electric Power University, Baoding \\ 071003,Hebei, China \\ b917367184@qq.com \\ "Li-Ya JIANG
}

Keywords: investment income private foundations donations crowding-out hypothesis

\begin{abstract}
The Private Foundationrely on donations and investment income to exist and develop, it is still unclear how these sources of funding may interact or even influence each other. This empirical paper, Chinese private foundations as the research object, tried to reveal whether and how commercial funding affect public donations, with a view to providing a scientific basis for private foundations' managers optimize the diversification of financing path and strategy. Conclusion is: commercialization of non-public funds will not bring obvious crowding-out effect on social donations, but it cannot be generalized.
\end{abstract}

\section{Introduction}

Purpose of existence determines the difference between Enterprises and non-profit organizations such as foundations. Enterprises conduct business and investment according to the goal of maximizing profits, for the purpose of profit to profit; While Non-profit organizations should carry out charitable activities, according to the goal of maximizing public welfare, for the purpose of serving the community. People traditionally believe that the foundation and other non-profit organizations must be split with the market and cannot carry out any business or investment activities, otherwise it will deviate from the public mission. In fact, the existence of non-profit organizations lies in the purpose of public welfare, rather than means of income. Non-profit organizations need to obtain resources from the market and use market approaches to improve the efficiency of charity. Among them, the commercial financing behavior of private foundations is increasing. In 2004, the State Council issued the "Foundation Management Regulations", stripping private foundations from the raised funds. By the end of 2015, the national private foundations has reached 3316, accounting for $68 \%$ of the total Foundation. In theory, the income of private foundations may be composed of four parts: donations, service income, government grants and investment income. But in fact, donations and investment income accounted for the vast majority of the revenue of private foundations; According to the China Foundation center, only 3.4\% of private foundations in 2014 received government subsidy income, but there is no service revenue. Donations is the result of non-market, while investment income is form market, so the question arises: whether the different sources of funding may interact with each other and even affect?

By looking up the literature, there are few related researches at present. Foreign scholars have made a lot of empirical research on the "crowding-in" and "crowding-out" disputes of government grants on private giving to nonprofit organizations. Kim Gregg, G. Van RyzinMirae and other scholars believe that the presence of government funding will cause crowding-out hypothesis and then displace or discourage private giving. WhileOkten and Weisbrod (2000) found no significant relationship between private and public funding sources for non-profit organizations across various nonprofit sectors. In addition, some scholars believe that there is the possibility that government funding may leverage or encourage private donations to nonprofit organizations. In China, there are only Houjun Dong, ZhuangXiaoli (2016) noting that government subsidies andcommercial funding will bring a significant negative impact on donations of non-profit organizations, in the the clearance of studying the combined effects of the operational efficiency of the non-profit 
organization for social contribution revenues, void of exploring the applicability of its private foundations. So we want to do this empirical study, Chinese private foundations as the research object, try to reveal whether and how commercial funding affect public donations, With a view to providing a scientific basis for rivate foundations' managers optimize the diversification of financing path and strategy and further enrich relevant theoretical research of the investment of private foundations.

\section{Study Design}

\section{Proposed Hypotheses}

Hypothesis is the premise of empirical research. According to the conclusion of HouJundong, ZhuangXiaoli (2016), Two hypotheses are put forward: Firstly ,In a non-public foundation commercial financing and donations may interact and even affect each other; The second hypothesis is that commercialization of non-public funds bring obvious crowding-out effect on social donations. The empirical Testing of first hypothesis will adopt technical correlation analysis, and the second is to further the use of regression analysis.

\section{Variable Selection and Model Construction}

In statistical research often log-transformed variables, which on the one hand can eliminate heteroscedasticity and transform non-linear relationship between the variables into a linear relationship to do parameter estimation, on the other hand can eliminate a huge difference in magnitude when the argument of magnitude studies are inconsistent. For this reason, studying made logarithmic transformation for a part of the variables .This article Opt the logarithm of donations as the dependent variable, which measures the social donations received by the sample. Non-profit organizations usually In the financial statement use the "investment income" project to indicate the amount of the organization of the proceeds of the commercial investment. This study selected the logarithm of investment return as independent variable to measure the commercial financing effect of non-public funds .In order to ensure the reliability of the results, we set other factors that may affect the income of donations for the control variables: the logarithm of welfare payments, organizational size and age of the organization, in which the public welfare payment is a direct expression of serving society and the performance of its public service mission, which will attract the social donations to a large extent. A detailed description of the variable is shown in table2-1.

Table 2-1Ddescription of variables

\begin{tabular}{lcl}
\hline \multicolumn{1}{c}{ Variable name } & Variable symbol & \multicolumn{1}{c}{ Variable description } \\
\hline donations & DON & the logarithm of donations \\
investment & INV & the logarithm of investment return \\
welfare payment & WEL & the logarithm of welfare payments, \\
organizational size & SCA & the logarithm of Net assets at the end of 2014 \\
Organizational age & AGE & how many years organization was founded \\
\hline
\end{tabular}

This paper selects multiple regression model to test the assumption that commercial funding will cause Crowding-out effect on private foundations' donations . Econometric model of the form set as follows:

$$
D O N=\beta+\beta 1 \cdot I N V+\beta 2 \cdot W E L+\beta 3 \cdot S C A+\beta 4 \cdot A G E+\varepsilon
$$

\section{Sample Selection}

In order to ensure the reliability of the research results, the researchers choose private foundations of a certain scale as samples, According to 3441 non-public foundations' data published in China Foundation Center(http://www.foundationcenter.org.cn/) ,We selected samples in accordance with the 2014 net assets ranking to collect the data of 2014 and filter samples containing 
the following features: Foundation in 2014 and beyond; Foundations of which Part of annual financial data have serious deficiencies; Foundations of which Part donations is zero income or negative. After screening, a total of 99 observational samples were obtained.

\section{Empirical Tests}

\section{Descriptive Statistics}

Table 3-1main variables are described. By comparison, due to the smaller difference between the mean and median of the dependent variable, data is in line with the normal distribution. Standard deviation of each variable is not 0 , indicating that investment income of different foundations, public spending and the size of the organization were some different, it can be inferred that donations earnings may be affected by this difference.

Table 3-1 Statistics

\begin{tabular}{lrrrrr}
\hline & \multicolumn{1}{c}{ age } & \multicolumn{1}{c}{ donations } & \multicolumn{1}{c}{ investment } & \multicolumn{1}{c}{ welfare } & \multicolumn{1}{c}{ scale } \\
\hline Mean & 5.10 & 5.1496 & 4.0619 & 5.5413 & 7.2920 \\
Median & 4.83 & 5.2983 & 4.0943 & 5.3706 & 7.5401 \\
Std. Deviation & 3.636 & 2.32686 & 1.95453 & 1.76707 & 1.65483 \\
Minimum & 1.00 & 0.00 & 0.00 & 2.94 & 3.09 \\
Maximum & 24 & 10.34 & 8.23 & 10.59 & 11.00 \\
\hline
\end{tabular}

\section{Correlation Analysis}

Study rely on correlation analysis technology to realize the test of hypothesis 1 . To make the results more reliable,, study successively conducted bivariate analysis and partial correlation analysis. Test results are shown in Table 3-2.

Table 3-2 bi-variate test results

\begin{tabular}{lllllll}
\hline \multirow{2}{*}{$\begin{array}{l}\text { Correlation } \\
\text { analysis }\end{array}$} & $\begin{array}{l}\text { Pearson } \\
\text { testing }\end{array}$ & hypothesis & Kendall hypothesis testing & $\begin{array}{l}\text { Spearman } \\
\text { testing }\end{array}$ & hypothesis \\
\cline { 2 - 7 } & Correlation & Sig & Correlation & Sig & Correlation & Sig \\
\hline Bi-variate test & 0.477 & 0.000 & $0.357^{*}$ & 0.000 & 0.510 & 0.000 \\
\hline
\end{tabular}

As shown in Table, Pearson correlation coefficient is 0.477 , and the test $\mathrm{P}$ value close to 0 , indicating that the two variables, investment income and donations, are positive significantly correlated, while Kendall hypothesis test, Spearman hypothesis test also proved this point, which is consistent with the hypothesis 1but is opposite to hypothesis 2.Studies suggest that it is reasonable. Because contact between investment income and income from donations is not direct, Increase the return on investment will result in an increase of net assets of the organization, organizational size becomes large, so that the organization has the ability to increase welfare spending, and thus attract public donations. In fact, two factors affect the linear correlation coefficient: one is directly related information, and second, through intermediate factors related information transfer. In the case of particularly large transmission of information, research needs to on the basis of relevant information exclude intermediate transferred factor and calculate direct correlation degree between the variables. To test whether the income from donations and investment income is directly related to research once again its partial correlation analysis. The results showed a correlation coefficient of -0.193 , 
showing two variables are negatively correlated, but the test $\mathrm{P}$ value of 0.06 is greater than 0.05 , indicating that this negative correlation is not significant. At this point, The first hypothesis is proven, while Assumption 2 is still a need for further verification.

\section{Regression Analysis}

Study rely on multiple regression analysis techniques to achieve the further hypothesis testing 2 . The regression results are shown in Table 3-3.

Table 3-3 Coefficients

\begin{tabular}{|c|c|c|c|c|c|c|}
\hline & & $\mathrm{B}$ & Std. Error & Beta & $\mathrm{t}$ & sig \\
\hline \multirow[t]{5}{*}{1} & (Constant) & -1.925 & 0.799 & & -2.410 & 0.018 \\
\hline & investment & -.253 & 0.133 & -0.213 & -1.903 & 0.060 \\
\hline & welth & 0.746 & 0.144 & 0.567 & 5.174 & 0.000 \\
\hline & scale & 0.561 & 0.193 & 0.399 & 2.908 & 0.005 \\
\hline & age & -0.023 & 0.045 & -0.037 & -0.524 & 0.602 \\
\hline
\end{tabular}

When performing multiple regression, we select the procedure of enter, the goodness of fit of the model was 0.76, which is better able to explain the dependent variable, and passed the test of significance. Investment income variable's coefficient is -0.253 , causing a negative impact on income from donations, but did not pass the significance test.so it cannot prove Hypothesis 2,and there are serious collinearityissue. Therefore, the study take step-wise regression way to test further, while the results show that only two variables(welfare payment, organizational size ) have passed the hypothesis test of 5\% significance level, and they are all positive effects. Since then, we draw conclusions: Hypothesis 2 is wrong and not all commercialization of non-public funds bring obvious crowding-out effect on social donations. Itcan not be generalized.

\section{Conclusions}

By the correlation analysis and regression analysis, the study was concluded: firstly, commercial financing and donations may interact and even affect each other; secondly, commercialization of non-public funds will not bring obvious crowding-out effect on social donations, but it cannot be generalized. We believe that people cannot simply say commercial financing will directly increase or reduce social income from donations, but depends on the use and manner of investment income whether is a part of obstacles or attraction to donations. If organizations use a large number of investment for public projects, and the Public have received service information, it will increase the attractiveness of donor tissue certainly; Conversely, if the organization used before donation income for investment benefit, and the purpose is for organization and even personal gain, That is bound to adversely affect the community, reducing income from donations. Of course, the transparent information system of private foundations will play an important role in disseminating, can be considered in the next study.

\section{References}

[1] MiraeKim,Gregg G. Van Ryzin. Impact of government funding on donations to arts organizations:A survey experiment[J].Nonprofit and Voluntary Sector Quarterly,2014(5).

[2] Okten, C., \&Weisbrod, B. (2000). Determinants of donations in private nonprofit markets. Journal of Public Economics, 75, 255-272. 
[3] Houjun Dong, ZhuangXiaoli. Donors will be concerned about the operational efficiency of non-profit organizations do? --- Evidence from China Foundation [J]. Chinese University of Geosciences, 2016 (5). 